\title{
Introduction from the Special Editor
}

\author{
Arkadiusz Misztal \\ Poland \\ amisztal@post.pl
}

The three papers that make up this number of KronoScope present different disciplinary approaches to ideas about temporality in philosophy and visual arts.

Andrew Buchanan (USA) discusses temporal practices in animation craft by addressing the phenomenological and technical potentials of the moving image arts. Animation practice and performance, Buchanan argues, conceptually and visually extend our senses of time by creating "temporally embodied" objects with strong, affective resonance in audience consciousness. Digital tools in particular offer new possibilities of rendering temporal objects by embedding the time line in their motion paths and in other interface elements. Instead of being confined to a series of individual frames, digitally animated objects exist through time and are capable of re-integrating the narrative time of the work with the subjective flow of a viewer's temporal experience. Because of the creation of new spatio-temporal relations, animation, Buchanan suggests, is best approached not as "a genre or a method of film production" but as "an expanded space of media convergence where both the actual and the unreal can be experienced."

Carla Gabrí (Switzerland) explores an experimental use of textile and paper in the conceptual video works produced by the contemporary Hungarian artist Dóra Mauer. In Proportions (1979) and Timing (1973/8o), Mauer implicitly invokes the problematic of spatial and temporal measurements to reveal conditions and dependencies involving the female body as encoded and inscribed in specific historical contexts. These two video works engage with the sociopolitical implications of measuring acts, along with their ensuing norms and standards, to reveal the otherwise invisible man-made rules that contribute to gender displacements and bodily experiences of exclusion and devaluation. By placing Mauer's works in the context of the history of paper formats, early motion studies, art making in socialist Hungary, and early time experiments, Gabrí seeks to re-evaluate their experimental aesthetics as directly driven by 
the subversive impulse to negate the idea of format as a powerful sociopolitical tool that is capable of constraining and shaping bodies, societies and thoughts.

David Jakobsen (Denmark) discusses the contribution and continuing relevance of the work of the New Zealand-born philosopher Arthur Norman Prior to the development of modern tense logic. The central focus of his paper is an examination of Prior's turn to medieval logic as a response to W.V.O. Quine's claim of the tenselessness of quantification over temporal entities in modern symbolic logic. Prior challenged Quine's view by demonstrating that there are no formal reasons for not accepting tensed propositions as being well-formed. In his efforts to formalize quantified tense-logic, Prior drew extensively on the medieval view of propositions and at the same time struggled with some of its implications and consequences. As Jakobsen argues, Prior "did not share the essential metaphysical view behind the medieval ideas of the truth-conditions for past- and future-tense propositions. Priorian presentism, for that reason, constitutes a halfway house between medieval and modern logic" and, as such, poses a challenge to contemporary forms of presentism.

The present issue of KronoScope is testimony to the multifaceted and interdisciplinary character of time-studies as animated by an impulse to rethink, revise and reassess problems of time in contemporary theory and art practices. I hope it will make for engaging and stimulating reading to all "time-smiths" interested in the specificity and complexity of contemporary conceptions of time and time-based media. 